\title{
A comparative analysis of global stakeholders' perceptions of the governance quality of the clean development mechanism (CDM) and reducing emissions from deforestation forest degradation (REDD)+
}

\author{
TEK NARAYAN MARASENI $\dagger^{*}$ AND TIM CADMAN \\ $\dagger$ University of Southern Queensland, Toowoomba, Queensland 4350, Australia; †Griffith University, \\ Nathan, Queensland, 4111, Australia
}

\begin{abstract}
The Clean Development Mechanism (CDM) and the nascent solution of Reducing Emissions from Deforestation and Forest Degradation (REDD+) are two global market-based mechanisms that link developed and developing countries. This paper provides a quantitative and qualitative analysis of global-level stakeholders' perceptions regarding the governance of the CDM focusing on environmental, social, economic, governmental and institutional participants. The research conducted was by means of an anonymous online survey using an analytical approach based on principles, criteria and indicators (PC\&I). It compares these findings with the results of a similar survey conducted by the authors on REDD+. Stakeholders from both developed countries and the developing countries were asked to rate the quality of these mechanisms against 11 performance indicators using a Likert scale (1-5). Overall, the results of CDM stakeholders from both developed and developing countries were very similar, indicating a common perception. The highest and lowest total scores were obtained from institutional and social stakeholders, respectively, demonstrating that these two groups have considerable differences in perceptions from other interests. CDM failed two indicators, 'equality' and 'resources', and passed all other nine indicators only marginally. The performance of REDD+ was much higher than CDM in all aspects of governance surveyed. The major differences were in 'equality' and 'problem solving', followed by 'transparency' and 'democracy'. If the CDM is to continue in the post-Kyoto period, some major systemic changes in governance are necessary. Here, there are some lessons to be learnt from REDD+.
\end{abstract}

Keywords: CDM; REDD+; carbon markets

\section{Introduction}

An approach to understanding governance in the last 20 years explains relations between state and non-state actors without relying on conventional 'top-down' or 'command-control' ideas about social-political interactions. The idea is one of interactions or collaborative effort for solving problems [1,2]. The governance of environmental issues at the global level - intergovernmental or otherwise - exemplifies these developments. It is often made up of relations between various actor types (non-governmental organisations, government and so forth) with decentralised institutional arrangements operating at

*Corresponding author. Email: maraseni@usq.edu.au 
multiple levels (international, national, subnational) [3]. This more 'networked' form of governance goes against the belief that 'regime' theory is the only way to analyse international relations [4]. Various initiatives using trade as a basis for sustainable development, including forestry, have given rise to the term non-state market-driven (NSMD) governance. Such initiatives cover a wide range of commodity sectors, including fisheries, agriculture, tourism, mining and trade [5,6]. It has been acknowledged that greater effort is required to research the aspects of governance quality in these and other international environmental policy processes [7]. It is also recognised that there the effectiveness of social 10 processes underlying decision-making should be measured [8].

Although there is a considerable impetus to make use of market-driven policy instruments in this policy field, experience with the Clean Development Mechanism (CDM) and the goal of Reducing Emissions from Deforestation and Forest Degradation (REDD+) show that carbon governance is a dynamic policy arena. Market instruments tackle climate

15 change using various public (governmental) and private (non-governmental/business) approaches to encourage greater sustainability in the management of scarce resources with the objective of reducing greenhouse gas (GHG) emissions. An important question for global marketing mechanisms (such as $\mathrm{CDM}$ and REDD+) is whether structural and procedural aspects will be given sufficient weight so that stakeholders may participate [9]. The

20 success of such international mechanisms will require governance arrangements that reduce emissions at scale (i.e. solve the problem), as well as being transparent and inclusive. Global decision-making processes will need to engage representatives of a range of non-state interests, including forest dwellers, civil society and business [10]. The decisionmaking must accommodate a wide range of interests, both groups who are most threatened

25 by climate change and the general public [8].

These systems of governance have become numerous, but universal rules and standards continue to be elusive [11,12]. There are no standards to ensure institutional quality of governance (rather than operational-level performance) for initiatives active within the sustainable development policy arena, and against which competing programmes can be measured and compared. Yet poor governance can increase costs and result in a negative outcome such as a reduction in credit rating [13]. Accordingly, there is a need to remove the unpredictability stakeholders can experience when engaging with a given project or programme, especially if their position caries more credibility than it would otherwise. This might be the case if, e.g. a national leader known to be sceptical of climate change arguments became active in seeking a climate change treaty.

A model of analysis based on principles, criteria and indicators (PC\&I) can provide a consistent framework for evaluating governance institutions as they are expressed at multiple scales - global, regional, national and local [5]. Using this approach, this paper provides a quantitative and qualitative analysis of global-level stakeholders' perceptions

40 regarding the governance of the CDM, focusing on environmental, social, economic, governmental and institutional participants. The paper compares these findings with the results of a similar survey conducted by the authors on the emerging 'carbon' market mechanism REDD+.

\section{CDM at a glance}

45 The historical achievement of the Kyoto Protocol (KP) was to set collective, legallybinding, emissions-reduction targets of at least $5.2 \%$ of 1990 levels during the period 
2008-2012. In order to realise this target in an efficient way, the KP adopted three flexible market-based mechanisms. Of these, only the Clean Development Mechanism (CDM) links developed and developing countries and is truly global. The CDM is designed with twin objectives: to help investors (developed countries or their approved organisations) meet their emission reductions targets cost-effectively and help developing countries achieve sustainable development [14,15]. The first CDM project was registered in 2004 in Brazil. The number of registered CDM projects has grown from 62 in 2005 to 1107 in 2011 [16]. By the end of 2012, approximately 5300 projects in 78 developing countries were registered with the CDM [16].

Along with the number of registered CDM projects, the CDM market also grew exponentially: rising to a market value of U\$32.8 in 2008 from US\$2.6 billion in 2005 $[17,18]$. The demand for CDM projects was significantly increased as a consequence of their acceptance into the European Union Emissions Trading Scheme (EUETS), and several other voluntary and national carbon markets. There is a considerable concentration of projects on both demand (developed countries) and supply sides (developing countries). Of all registered projects, $50.86 \%$ are from China. In contrast, India has $19.22 \%$, Brazil $4.46 \%$, Mexico $3.02 \%$ and Malaysia $2.33 \%$. Roughly $75 \%$ of projects are in 'BRIC' countries (Brazil, Russia, India and China). These emerging economies have sufficient capability to reduce emissions [19]. European countries are the largest consumers of CDM project-related credits because of their legal obligations. About $80 \%$ of the total CDM investments are from the United Kingdom (39\%), Switzerland (10.9\%), Netherlands (9.1\%), Sweden (6.5\%) and Germany (3.6\%). Japan is also a significant player $(9.6 \%)$ [16].

The CDM has performed less well since 2008 for various reasons, including the Global Financial Crisis (GFC); the ending of the first commitment era of the Kyoto Protocol; and a lack of commitment from America and some of the other previously more committed countries, such as Canada and Japan [20]. As a result, in 2012 alone, CDM carbon prices dropped by $70 \%$ and were projected to fall further over coming reporting periods $[21,22]$. Nevertheless, the CDM has achieved much. Billions of tonnes of greenhouse gases (GHG) have been prevented, avoiding at least US\$3.6 billion in negative social impacts. If these projects had been implemented in developed countries, it would simply not have been possible to get such a cost-effective reduction of emissions. Over US\$215 billion has been mobilised in developing countries. This has led to capacity development. People have become empowered and have gained valuable experience in developing climate solutions [21,22].

There are several issues in CDM: the eligibility of $\mathrm{HFC}$-and $\mathrm{N}_{2} \mathrm{O}$-related projects has undermined the sustainable development objective; the provision of the unilateral $\mathrm{CDM}$ project activity has benefitted the resource-advantaged countries, rather than the intended least-developed countries and has reduced the chance of technology transfer; the rate of GHG emissions from China and India, which have higher numbers of CDM projects and have been issued higher numbers of CERs, has been growing faster than the highest emitting Annex I countries; and there is huge regional disparity in terms of CDM number and amount of investments [23-25]. These and other problems have led key stakeholders within CDM itself to argue that the mechanism is 'imperilled', raising questions about future viability. Some may not mourn its demise; its collapse, however, would undermine what political consensus there is for global carbon markets [26]. 


\section{REDD+ at a glance}

The net annual change in forest area in the period 2000-2010 is estimated to be 5.2 $\mathrm{M}$ ha. Deforestation and forest degradation account for about $20 \%$ of global GHG emissions, more than the entire global transportation sector and second only to the energy sector [27]. Therefore, without combating deforestation and forest degradation, the $2{ }^{\circ} \mathrm{C}$ (or $450 \mathrm{ppm}$ of $\mathrm{CO}_{2}$ ) climate stabilisation goal will not be reached [28]. Although the $\mathrm{CDM}$ also recognises the role of forests in mitigating climate change, it initially limited its scope to afforestation and reforestation activities, and its ability to achieve intended outcomes was questioned. The transition in UNFCCC negotiations via the Bali Action Plan to the reduction of emissions from deforestation and forest degradation by means of REDD+ in COP15 may reflect this reality.

REDD + aims to counter deforestation and forest degradation by delivering performancebased payments to forest managers in developing countries for the conservation and/or increase of forest carbon stocks [29]. REDD+ has a range of objectives, the foremost being the reduction of emissions from deforestation and forest degradation; forest conservation and sustainable management; and increasing forest carbon [30]. With the recognition of REDD+, developed countries may offset their GHG emissions through payments to developing countries that wish to participate in REDD+.

REDD+ has played a significant role in the transformation of North/South politics. Moreover, a number of agreements have been reached regarding REDD + , even if these are not legally binding [31]. Developing countries stand to gain considerably from REDD+ financially, as forestry will be a major component of funding of $\$ 100$ billion referred to in the Copenhagen Accord [31]. The mechanism gained further recognition at COP 16 in Cancun, with Parties committing to develop a framework for negotiations for a globallevel REDD+ agreement [32]. A 'green climate fund' was established, and the onus was placed on developed countries to provide $\$ 30$ billion of climate finance to developing 30 countries by 2012 [33]. The importance of social and environmental safeguards was also highlighted in COP17 in Durban, leading to the development of policy and procedure documents aimed at protecting safeguards [33,34].

\section{Approach and method of evaluating the quality of governance}

Global governance is assessed through the development of an analytical framework linking participation and deliberation to two central organising arrangements within global environmental governance: structure and process. Structure refers to those participants that are accepted as legitimate actors. Process concentrates on the procedural arrangements used for making and implementing decisions. Two principles express the norms affecting participation and deliberation: participation is understood to be significant, (i.e. participants' involvement is genuine, not token); and deliberation is understood to be productive, (i.e. negotiations result in 'products' that are capable of being put into effect). Using the separation between participation as structure and deliberation as process, the values underlying these principles are expanded by the use of criteria and indicators that identify the extent to which a specific institution, or associated programme, policy initiative, market mechanism, or project (or other form of sub-institutional arrangement) matches up to these desired values [5].

Principles and criteria are not created for measurement, but represent desired elements in the determination of the extent of compliance. They are, therefore, associated with 
indicators, which are used to identify quantitative or qualitative variables, and express the condition of the governance system in question as it performs against the relevant criterion and principle. The location of these components within this sort of framework is explicitly hierarchical, i.e. located consistently, to permit the evaluation of indicators to criteria and criteria to principles. Consistency refers to the correct placement in the framework. Consistency in placement avoids overlap or duplication and ensures the correct relation to higher order attributes [35]. This use of principles, criteria and indicators facilitates the evaluation of institutional performance and overall legitimacy [5].

Using these principles, criteria and indicators, this paper analyses stakeholders' perceptions regarding the governance of the CDM and REDD + at the global level, focusing on environmental, social, economic and governmental participants and the institutions themselves. A wide range of individual and organisational representatives related to CDM and REDD+ were surveyed (in March 2010, for REDD+ stakeholders and November 2010, for CDM stakeholders) using Survey Monkey (surveymonkey.com). On the basis of their own perspectives, participants were asked to rate their perceptions of governance using the 11 indicators of Table 1 by means of a scale from 'very low' to 'very high' (1-5). Indicatorlevel results were aggregated to the criterion level, which in turn contributed to the principle score overall. The two principle-level scores were added to produce an overall result, out of 55. Participants in the survey were also invited to make written comments for each indicator. Qualitative comments from respondents in the CDM survey are also included below.

An internet link to a predesigned anonymous questionnaire was sent to $800 \mathrm{CDM}$ stakeholders from around the world and 800 stakeholders from REDD + . Email addresses of the contact persons for the stakeholders were collected from publicly available participants' lists from training workshops and information sessions advertised online, as well as websites. A total of $72 \mathrm{CDM}$ stakeholders commenced the survey, but only 45 completed the survey ( 22 from environment, 6 from the social, 4 from economic, 1 from the government, 4 from institutional and 8 from other sectors). Similarly, 164 REDD+ stakeholders commenced the survey, but only 44 completed the survey. There are many reasons (as reported by follow-up emails) why survey response and attempts rates are so much higher than the completion rate. Firstly, online surveys have generally lower participation rates than other forms of survey technique [36]. Secondly, it could take up to one hour to answer all the questions, if qualitative comments were included. Thirdly, analysis only considered the

Table 1. Hierarchical framework for the assessment of governance quality.

\begin{tabular}{lll}
\hline Principle & Criterion & Indicator \\
Significance of participation & Interest representation & Inclusiveness \\
& & Equality \\
& & Resources \\
& Organisational responsibility & Accountability \\
Productive deliberation & Decision-making & Transparency \\
& & Democracy \\
& Agreement \\
& Implementation & Dispute settlement \\
& & Behavioural change \\
& Problem solving \\
& Durability \\
\hline
\end{tabular}

Source: Cadman [5]. 
respondents who completed all survey questions. Fourthly, in many developing countries, the internet is poor because of load shedding and interruptions in power supply.

Survey respondents were asked to classify themselves under six categories (environmental, social, economic, governmental, secretariat or other institutional component, and other), and to identify which region they came from (global North or global South). In the case of CDM, these sectors are broken down by geopolitical region (North/South - Developed/ Developing country). More detailed results in relation to REDD + are available elsewhere [37-39]. Finally, the total scores for each principle, criterion and indicator in the CDM survey were compared to the REDD+ survey results.

It was not possible to test whether there was any statistically significant difference between the means (averages) of these different types of stakeholders for three reasons: (1) the sample size of each subset was too small (lower than a minimum requirement of 30 in all cases); (2) given the very low response rate, it was unclear to what degree the samples are representative of the whole survey populations; and (3) the respondents were selfselected as belonging to different sectors (environmental, social, economic, governmental and institutional), i.e. they were not sufficiently homogeneous in nature for such analysis across surveys. Nevertheless, some interesting results were generated, and these are discussed below. It is not yet clear whether the mix of respondents is broad enough for the authors to be satisfied that they have covered the spectrum that is within the population. The approach is a novel one, and both the methods and analysis should therefore be seen as preliminary, requiring further research to determine if the trends identified are correct across the two universes of CDM and REDD+.

A number of further observations also need to be made about the results presented below. Respondents rated the mechanisms at the indicator level. Other global governance investigations have also questioned if qualitative data (as here) can be used to generate quantitative results. Converting of verbal descriptions such as 'low', 'medium' and 'high' into numerical results can lead to results that appear to have statistical authority and the semblance of exact science [40]. The authors accept that such results are indicative, rather than authoritative.

In this study, scores at the indicator level have also been aggregated for the purposes of generating findings at the criterion and principle levels, as well as the overall score. In some instances, this has resulted in a situation where the mechanisms did not perform well in one indicator but met the criterion-level threshold or did not meet the threshold for the criterion, but did meet the threshold at the principle level. These factors need to be borne in mind when examining the results for each survey. It must also be stated that the numbers of respondents are low. This may have resulted in the 'outlier' effect, where very low numbers of respondents in one group can overly influence the results (particularly here, in the cases of government).

\section{Results and discussion}

\section{$C D M$}

Scores for each sector are given in Table 2 (North) and Table 3 (South). Table 4 provides average scores across sectors and regions. Table 5 provides the comparative scores for $\mathrm{CDM}$ and REDD+ respondents by region and overall result. The tables are self-explanatory, but a few brief highlights are provided below.

Scores from both the global North and global South for CDM respondents follow the same trend, showing strong consistency in their perceptions. Institutional (secretariat) 
Comparative analysis of global stakeholder

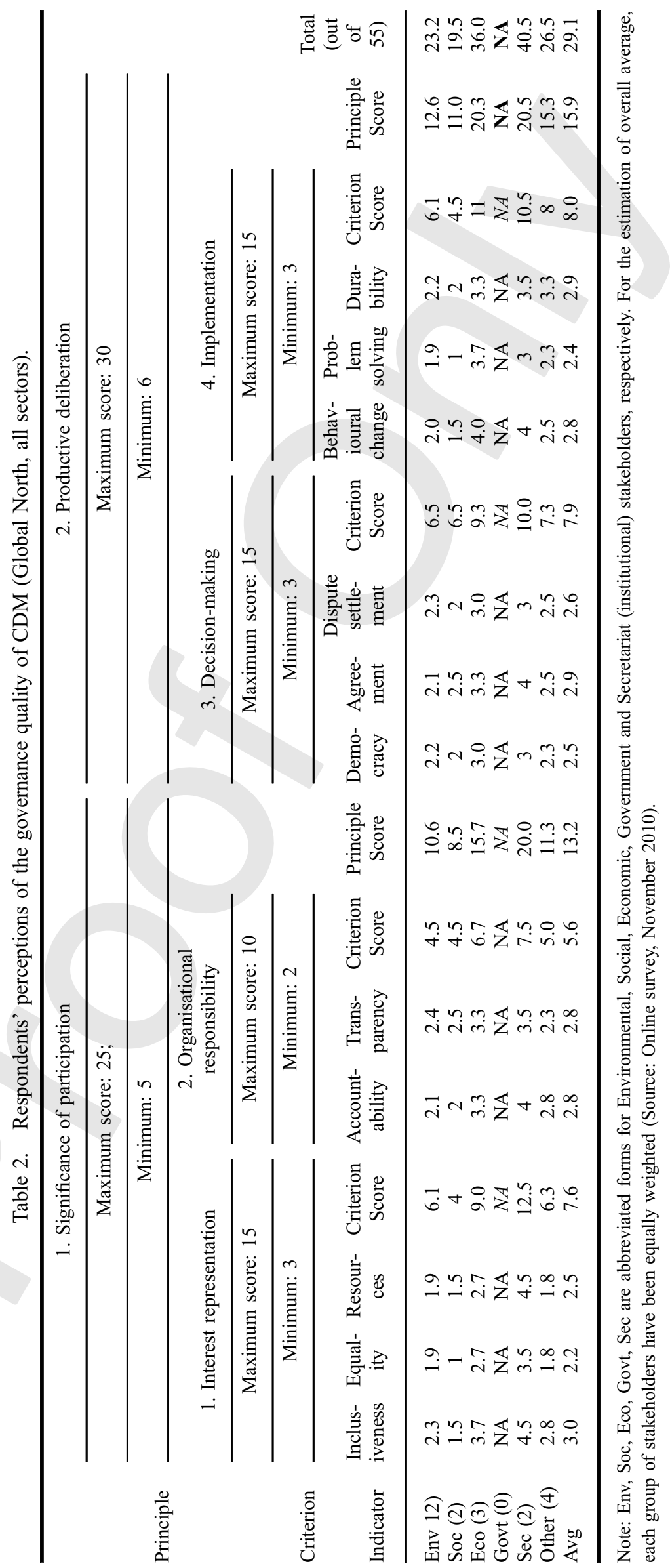


T.N. Maraseni and T. Cadman

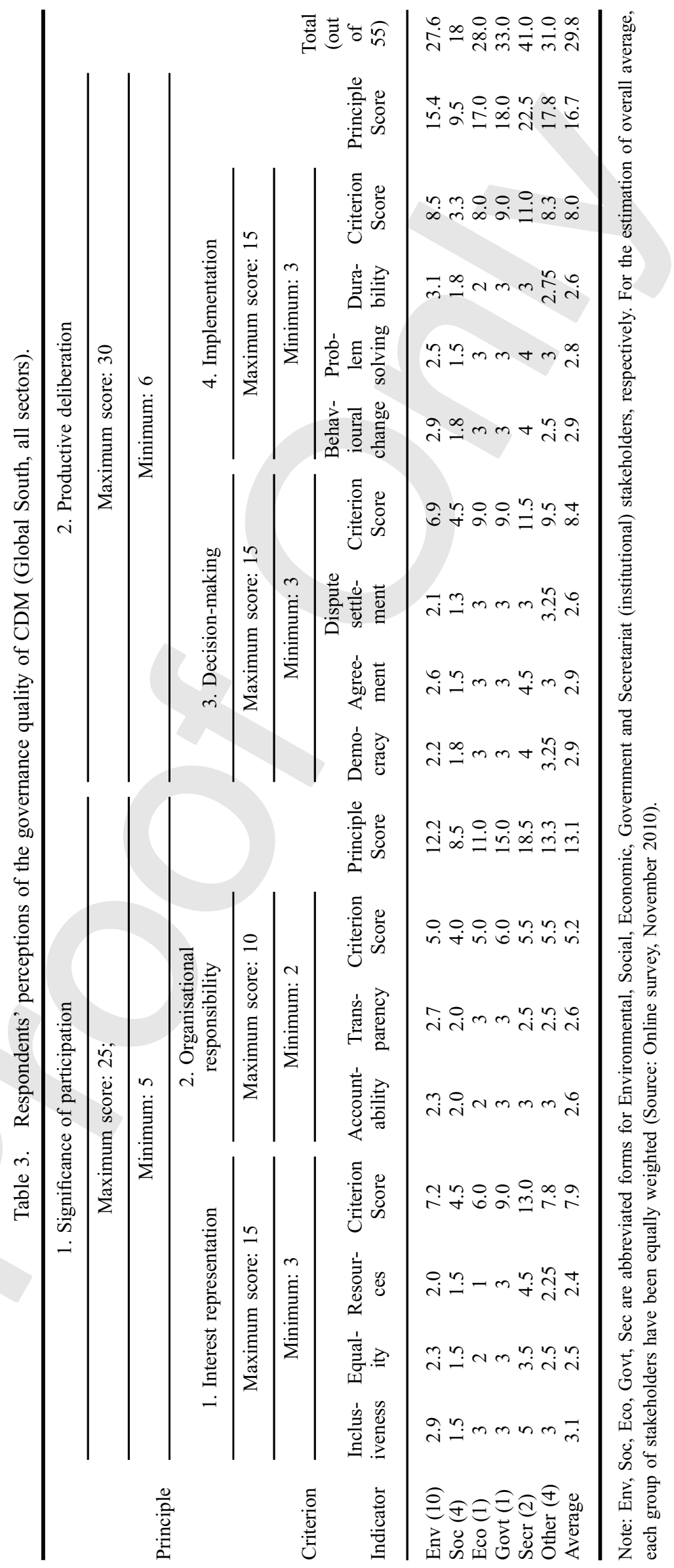


Comparative analysis of global stakeholder

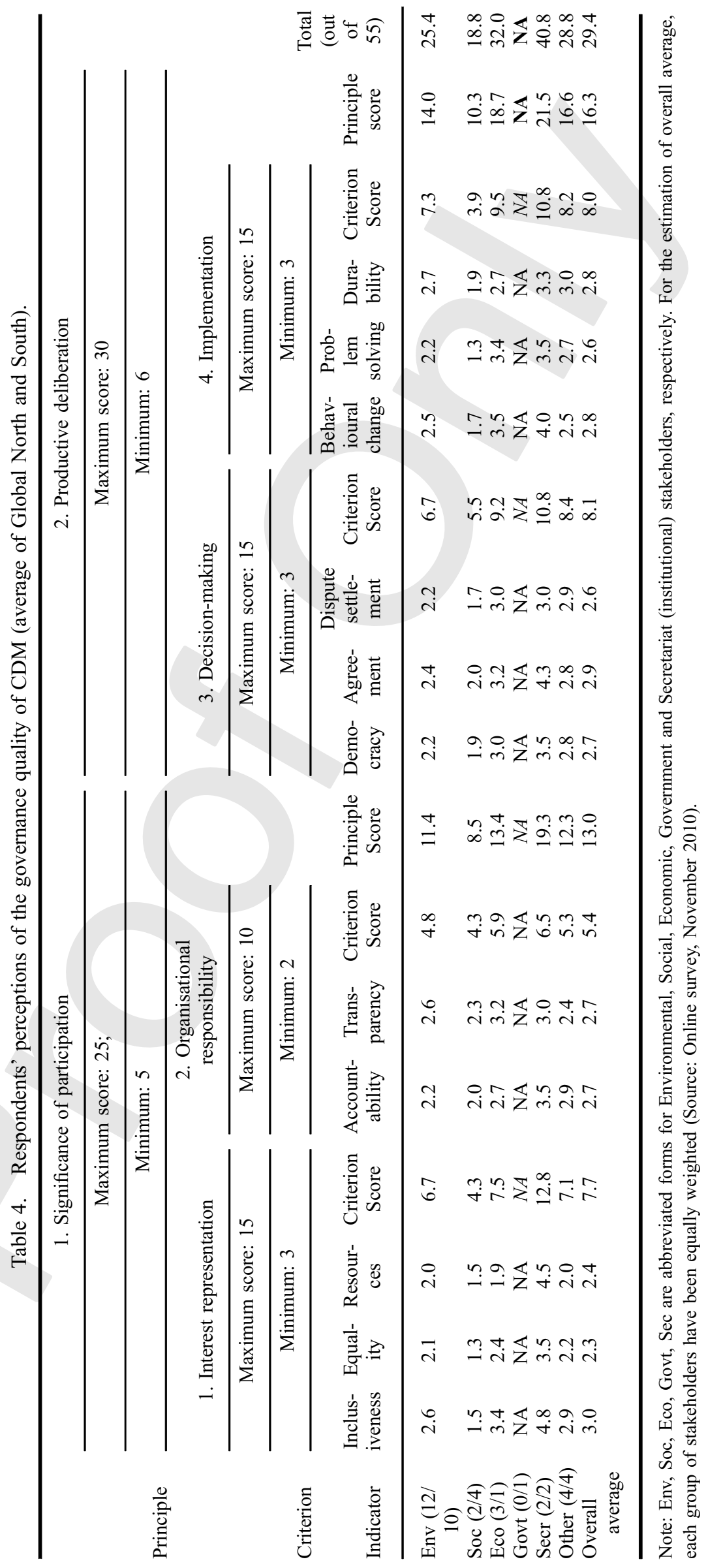


Table 5. Comparison of respondents' perceptions of the governance quality of CDM and REDD+.

\begin{tabular}{|c|c|c|c|c|c|c|c|c|c|c|c|c|c|c|c|c|c|c|}
\hline \multirow{5}{*}{ Principle } & \multicolumn{8}{|c|}{ 1. Significance of participation } & \multicolumn{9}{|c|}{ 2. Productive deliberation } & \\
\hline & \multicolumn{8}{|c|}{ Maximum score: 25 ; } & \multicolumn{9}{|c|}{ Maximum score: 30} & \\
\hline & \multicolumn{8}{|c|}{ Minimum: 5} & \multicolumn{9}{|c|}{ Minimum: 6} & \\
\hline & \multicolumn{4}{|c|}{ 1. Interest representation } & \multicolumn{3}{|c|}{$\begin{array}{l}\text { 2. Organisational } \\
\text { responsibility }\end{array}$} & & \multicolumn{4}{|c|}{ 3. Decision-making } & \multicolumn{4}{|c|}{ 4. Implementation } & \multirow[b]{4}{*}{$\begin{array}{l}\text { Princ- } \\
\text { iple } \\
\text { score }\end{array}$} & \\
\hline & \multicolumn{4}{|c|}{ Maximum score: 15} & \multicolumn{3}{|c|}{ Maximum score: 10} & & \multicolumn{4}{|c|}{ Maximum score: 15} & \multicolumn{4}{|c|}{ Maximum score: 15} & & \\
\hline \multirow{2}{*}{$\begin{array}{l}\text { Criterion } \\
\text { Indicator }\end{array}$} & \multicolumn{4}{|c|}{ Minimum: 3} & \multicolumn{3}{|c|}{ Minimum: 2} & & \multicolumn{4}{|c|}{ Minimum: 3} & \multicolumn{4}{|c|}{ Minimum: 3} & & \multirow[b]{2}{*}{$\begin{array}{l}\text { Total } \\
\text { (out } \\
\text { of 55) }\end{array}$} \\
\hline & $\begin{array}{l}\text { Inclus- } \\
\text { iveness }\end{array}$ & $\begin{array}{l}\text { Equal- } \\
\text { ity }\end{array}$ & $\begin{array}{l}\text { Resour- } \\
\text { ces }\end{array}$ & $\begin{array}{l}\text { Criterion } \\
\text { Score }\end{array}$ & $\begin{array}{l}\text { Account- } \\
\text { ability }\end{array}$ & $\begin{array}{l}\text { Trans- } \\
\text { parency }\end{array}$ & $\begin{array}{l}\text { Criterion } \\
\text { Score }\end{array}$ & $\begin{array}{l}\text { Principle } \\
\text { Score }\end{array}$ & $\begin{array}{l}\text { Demo- } \\
\text { cracy }\end{array}$ & $\begin{array}{c}\text { Agree- } \\
\text { ment }\end{array}$ & $\begin{array}{l}\text { Dispute } \\
\text { settle- } \\
\text { ment }\end{array}$ & $\begin{array}{l}\text { Criterion } \\
\text { Score }\end{array}$ & $\begin{array}{l}\text { Behav- } \\
\text { ioural } \\
\text { change }\end{array}$ & $\begin{array}{l}\text { Prob- } \\
\text { lem } \\
\text { solving }\end{array}$ & $\begin{array}{l}\text { Dura- } \\
\text { bility }\end{array}$ & $\begin{array}{l}\text { Criterion } \\
\text { Score }\end{array}$ & & \\
\hline Global N CDM (23) & 3.0 & 2.2 & 2.5 & 7.6 & 2.8 & 2.8 & 5.6 & 13.2 & 2.5 & 2.9 & 2.6 & 7.9 & 2.8 & 2.4 & 2.9 & 8.0 & 15.9 & 29.1 \\
\hline Global N REDD+ (11) & 3.3 & 3.5 & 2.5 & 9.9 & 3.0 & 3.4 & 6.4 & 16.2 & 3.4 & 3.5 & 3.2 & 9.9 & 3.7 & 3.8 & 3.6 & 11.1 & 21.0 & 37.2 \\
\hline Global S CDM (22) & 3.1 & 2.5 & 2.4 & 7.9 & 2.6 & 2.6 & 5.2 & 13.1 & 2.9 & 2.9 & 2.6 & 8.4 & 2.9 & 2.8 & 2.6 & 8.0 & 16.7 & 29.8 \\
\hline Global S REDD+ (31) & 3.8 & 3.4 & 2.4 & 9.5 & 3.3 & 3.5 & 6.7 & 16.2 & 3.4 & 3.3 & 3.1 & 9.7 & 3.6 & 3.6 & 3.5 & 10.5 & 20.2 & 36.4 \\
\hline Global avg CDM (45) & 3.0 & 2.3 & 2.4 & 7.7 & 2.7 & 2.7 & 5.4 & 13.0 & 2.7 & 2.9 & 2.6 & 8.1 & 2.8 & 2.6 & 2.8 & 8.0 & 16.3 & 29.4 \\
\hline $\begin{array}{l}\text { Global avg REDD+ } \\
\quad(44)\end{array}$ & 3.5 & 3.4 & 2.4 & 9.7 & 3.1 & 3.4 & 6.5 & 16.2 & 3.4 & 3.4 & 3.1 & 9.8 & 3.6 & 3.7 & 3.5 & 10.8 & 20.6 & 36.8 \\
\hline
\end{tabular}

Note: For the estimation of global average, each group of stakeholders have been equally weighted (Source: Online survey, November 2010 for CDM and March 2010 for REDD+ data). 
respondents, North and South, provided the highest total scores (40.5/55 cf 41/55), whereas social respondents provided the lowest total scores $(19.5 / 55 \mathrm{cf}$ vs $18 / 55)$. Both the northern and southern social respondents provided the lowest scores for all indicators: none of the 11 indicators have scored $>2.5$; the scores from institutional respondents for all the 11 indicators were $>3.0$. On the basis of the perspectives of social respondents, the CDM fails on both principles: significance of participation was rated 8.5/25 and productive deliberation 10.5/30. The same goes for the criteria and indicators, whereas institutional respondents' scores resulted in a 'pass' in all principles, criteria and indicators (see Tables 2-4). Clearly, there is a difference in perceptions regarding the governance quality of CDM between these two groups.

Overall, the results of CDM stakeholders from both the global North and global South were very similar (29.1/55 v 29.8/55), indicating a common perception. Moreover, the overall average of all stakeholders shows that CDM has marginally passed both principles (significance of participation was rated $13 / 25$ and productive deliberation 16.3/30) and all four criteria. In terms of the indicators, the highest average score was given for inclusiveness $(3 / 5)$ and the lowest for equality (2.3/5). All indicators, except equality and resources $(2.4 / 5)$, were marginally more than 2.5 and equal to or less than 3 , and therefore also 'passed' the quality-of-governance test (Table 4). Equality (i.e. the balance of power relations between stakeholders) and resources (i.e. the provision of technical, informational, financial or institutional capacity) clearly need to be examined further in CDM governance.

Non-state respondents provided the most comments, and both positive and negative views were evenly spread across geopolitical regions. One (Southern) governmental respondent also added a perspective. One non-state respondent felt that because the mechanism was 'flawed', to 'expect improvement' of the CDM and related undertakings was simply not possible. A number of respondents provided their opinions as to what project types ought to be included with the mechanism. Some focused on renewable energy or more equitable energy projects with an emphasis on poverty alleviation. The problem of additionality was also a concern, and the observation was made that in order to deliver 'tangible' outcomes, sustainable development needed to be defined in a more 'thorough and realistic' manner. The government representative also saw a link between additionality and equality: i.e. CDM projects might end up compensating already-established initiatives that did not in fact generate actual additional emissions reductions. This representative wanted better definitions to avoid this problem. Another was of the view that the CDM could not be improved because it had never been meant to be inclusive and could not work if it was.

Despite the high rating for inclusiveness in the overall results, comments varied considerably: for some, the CDM provided a degree of inclusiveness for social interests; others questioned how rigorous this really was. According to one person, there was certainly 'frequent consultation', including the use of independent, third-party (non-state) certification programmes, such as the Forest Stewardship Council (FSC). Others contradicted this viewpoint, arguing for more direct state involvement in the verification of 'local community' involvement. This was because projects made use of people purely to maintain their own existence; in actual fact, the longer term benefits for the community were 'minimal' in view of the 'amounts traded'.

Equality received the lowest score and also generated a number of negative comments. One respondent did qualify negative sentiments by commenting that the principle of 'one country one vote' was observed within the high-level discussions of the CDM, but at the 
project level, it ' $\mathrm{d}[\mathrm{id}]$ not exist.' Echoing other participants, the government respondent believed that investor interests largely drove the mechanism and even there, 'foreign investors' received preferential treatment in comparison to 'local partners', local communities were at the 'end of the queue'. One respondent thought it would be a better system if it showed particular favour to the poorer developing countries, and focused on 'household'specific initiatives-level projects. For another, the 'relaxed' nature of definitions and meth-

10 odologies also needed to be tightened, otherwise the CDM and associated projects would continue to favour the 'might of capital' over and above 'less powerful' stakeholders.

As for the need for resources, or capacity building, the government respondent wanted to see more devolution of authority to DNAs and capacity building for them at the national level, as well as an extension of the DoEs into regional areas. Here, there was a

15 link to accountability, with a suggestion that the CDM required systems for 'monitoring at various tiers with local, regional and central' authorities and such tools as 'check lists' to ensure compliance.

A number of perspectives were offered concerning the democracy of the CDM. According to one survey respondent, the CDM was, at its very best, little more than a process of 20 'low-intensity' and, at worst, an 'oligonomy', consisting of a small world of potentially colluding sellers and buyers. At a 'macro' level, it could be seen to be democratic because project participants were generally consulted and agreed to be involved, but this was not the case at the micro or 'local' level. All the while the CDM involved large amounts of capital, it reaffirmed the power of interests with access to such resources, and it would do 25 little for those with 'socio-environmental' needs, who were at the margins of 'political and economic power'; yet, these were precisely the interests who most needed to benefit from the mechanism. According to another, one hindrance to this ever happening was the domination of decision-making by economic interests; the only solution was to remove decision-makers who had 'financial or vested interests' at the Executive Board (EB) level. The governmental participant also thought that communities were 'not involved' in the decision-making process and were 'largely unaware' that the projects were even occurring.

The market-driven basis to the CDM also impacted on the kinds of agreements reached - as well as CDM's effectiveness in settling disputes. One respondent thought that, as a mechanism, CDM was 'the most rigid and conservative worldwide' and in need of 'improvement'. Another did not want the CDM to deliver agreements solely in relation to offsets; instead, there should be more emphasis on 'environmental quality' in areas where the CDM was being implemented. Disputes were usually settled 'behind closed doors' according to one respondent who had attended EB meetings - out of the light of public scrutiny. The process was a 'vulgar display' of corruption. Dispute settlement was better in 'theory' than it was on the ground. Communities could end up as 'hostages' to development interests and the project implementers, and where there was outright conflict, the difficulty in taking anything to court was 'extreme'. The one respondent who was positive about the CDM's dispute settlement capacity pointed to the large number of projects worldwide as proof that that it was conflict free.

As noted above, the discussion here focuses only on Northern and Southern perceptions for comparison with the CDM. In the case of Northern respondents, REDD + passed both principles (significance of participation was rated 16.2 out of 25 and productive deliberation 21 out of 30), as well as all the criteria and indicators (Table 5). The views of 
Southern respondents were also similar. The total overall score for Northern respondents was slightly higher than that of the score of global south stakeholders (37.2/55 cf. 36.4/ 55). The highest average scores were given for two indicators, transparency and democracy (both scored 3.4/5) and the lowest average score was given for resources (2.4/5).

For Northern governmental representatives, interest representation depended 'a lot' on who was involved in negotiations and who was chairing. Northern governmental respondents rated their perceptions of inclusiveness at a lower level than Southern governmental participants. One commented that the UNFCCC Parties were possibly dealt with 'too equally', commenting further that since various countries had 'more interest' than other countries in the negotiations, the 'one country, one vote' system in the UN was not really 'adequate for REDD+'. For another, even managing to get their interests 'on the table' was not easy, a view echoed by another respondent who sympathised with NGOs as this was made even more difficult for them. The view was also expressed that social and environmental governance had been 'adequately addressed' in REDD+, but there had been a failure to address issues critical to specific interests, including forest communities, who were not receiving equal treatment. Southern respondents answered in greater numbers and had a wider range of views than their Northern governments, depending on their region; those from South East Asia and Africa were largely favourable; another from Latin America made the point that non-state actors had little chance of influencing the process. There were, however, 'various forums' which could be used to feed into REDD+ negotiations, even if the 'official process' did not provide space.

Non-state respondents from developing countries rated inclusiveness higher than such respondents from developing countries. One observed that the degree to which issues of importance to NGOs were noted was medium to high, but the extent to which their views led to actual results was low. Another felt this was because 'the political process of the negotiations' was dominated by just a 'few countries'. Another added that to be inclusive, it was necessary to include marginalised voices in society, especially women. Concerning equality, one respondent did not believe interests outside of governments would ever be treated equally. The process was effectively driven by the Conference of Parties, and was set up to provide a forum for them with the express purpose of reaching agreement concerning the post-2012 regime. Despite this reality, another respondent commented that there was some effort paid to treating everyone equally, but that it was 'very hard' to ensure everyone was pleased.

In terms of democracy, following other indicators, views were also along geographical lines. One Latin American respondent commented that 'large countries' did not 'favour the environment, but economic interests'. With regard to democracy, one respondent considered that efforts were made in the negotiations to be democratic, but the default UN preference for consensus was 'time consuming' as well as being 'inefficient'. Perspectives on how agreements were made were mostly favourable, although there was one interesting observation made that Western business interests 'almost always triumph'. At times, however, this could be 'mitigated with noise' made by developing countries. Views on dispute settlement reflected those of other survey respondents.

\section{Kyoto and beyond}

Despite implementation of the Kyoto Protocol and several other national and international policies, global greenhouse gas (GHG) emissions from 2000 to 2010 grew more quickly $(2.2 \% / \mathrm{yr})$ than in each of the three previous decades $(1.3 \% / \mathrm{yr})$ and reached $49( \pm 4.5) \mathrm{Gt}$ 
$\mathrm{CO}_{2} / \mathrm{yr}$ in 2010 [41]. Since then, the problem has been further complicated as the Kyoto Protocol has entered what is probably its final commitment period (2014-2015), covering only a small fraction of global GHG emissions, with limited participation or non-participation by a number of key industrialised ('Annex I') countries, including the United States, Canada, Russia and Japan [42]. Without action from the major polluters on GHG reduction, regardless of Annex I and non-Annex I countries, the overarching target of global emissions reduction could not be achieved [43].

As at June 2014, there is a great deal of uncertainty in current climate change negotiations as part of the UNFCCC. This hinges upon what will be contained in the new institutional arrangements for reducing emissions, to be developed in the second commitment to the Kyoto Protocol. Parties committed to reducing emissions by $18 \%$ below 1990 levels over the period 2013-2020 [44]. Originally, 37 countries made commitments to reduce emissions, but more countries are expected to do so in future [45]. In addition, it is not yet clear exactly what mechanisms will be put in place to reduce emissions. The old architecture favours market-driven mechanisms, the so-called 'flexible mechanisms': the CDM, Joint Implementation (JI); and International Emissions Trading. As noted, the CDM is largely for developing countries who have not signed up to cuts, but still want to reduce emissions, while JI is for largely developed countries who have agreed to emissions reductions. Both schemes generate reduction units that can be purchased to 'offset' industrial emissions, thereby stimulating emissions trading and emissions trading schemes [46].

Theoretically, the more countries sign up to cuts, the fewer countries will be available for CDM projects, reducing the market. Ironically, the CDM, like JI, has been heavily impacted by the Global Financial Crisis. This has reduced industrial activity and the very emissions in need of reduction. At the same time, the relative success of these mechanisms has meant that the market for 'carbon credits' is somewhat saturated, and there are not enough buyers, and not enough scarcity of credits to drive up the price. But beyond market forces, there is a challenge to the validity of market mechanisms to reduce emissions. Some developing countries object to 'carbon credits', and prefer instead to see incentives in the form of payments to reduce emissions.

30 Perhaps the most influential emerging mechanism to be caught between these opposing approaches is the initiative to reduce emissions from deforestation and forest degradation in developing countries known as 'REDD+' [47-50]. Discussions are underway about its future. Since many hundreds of millions of dollars have been spent on pilot studies and protoschemes under REDD+, it is likely that it will act as the main fulcrum for the 'market/non-market' debate as it unfolds between now and the Lima Conference of Parties (COP), in December 2014 and in 2015, in the lead up to the Paris COP, where the arrangement for 2013-2020 are expected to be settled.

\section{Conclusions and recommendations}

Overall, the performance of REDD+ was much higher than the CDM in all indicators, and this is reflected in all criteria and principles (Table 5). The total score for CDM respondents is 29.4 (out of 55) in contrast to 36.8 for REDD+ stakeholders. Major differences were in 'equality' (2.3 vs. 3.4) and 'problem solving' (2.6 vs. 3.7), followed by 'transparency and 'democracy' (both, 2.7 vs. 3.4). At the indicator level, however, there is one similarity: resources, which in both mechanisms scored 2.4 out of 5 and therefore merits a 'fail'. 
This may show an underlying problem in global environmental governance, especially in the context of intergovernmental policy development and implementation, where governmental participants have greater access to resources than other, non-state, stakeholders, who must often generate the necessary capital themselves if they want to have a presence in negotiations. The universal low rating for resources in both CDM and REDD+ may reflect the reality that few stakeholders have the wherewithal to participate in global governance. Although the participatory rhetoric at the global level has increased since Rio, and over the last 20 years, it is not always matched by reality. Given the mix of actors in contemporary global environmental governance, the methods of participation and deliberation associated with negotiations are as important as the decisions made about any issue. In view of the stakeholder-based model of contemporary governance, there are increased expectations about the role of non-state actors. This has created some dynamic tensions in the relations between non-state and state actors in the formulation of policy at the international level and its implementation at the regional and/or national/sub-national levels.

If the CDM is to be continued in the post-Kyoto period, it would be wise to spend more time on seeking to improve the governance arrangements, stakeholder participation in CDM-related policy deliberations and project implementation. Rather than concentrating exclusively on the economic and technical aspects of crediting emissions reduction, it would be wise to learn from REDD+ - especially in the criteria where there is such a discrepancy between CDM and REDD+. Nevertheless, more research across a larger number of participants in both these mechanisms is required to determine if these results are indicative of broader perceptions. But in view of the constant changes of personnel within global 'policy populations', finding a stable cohort of respondents will continue to be difficult.

\section{Acknowledgements}

We cordially thank the anonymous referee and Dr Michael Brett-Crowther for their kindness.

\section{References}

[1] Kooiman, J., 1993, Social-political governance: Introduction. In: J. Kooiman (Ed.) Modern Governance: New Government Society Interactions. (London: Sage), pp. 1-8.

[2] Kooiman, J., 2000, Societal governance: Levels, models, and orders of social-political interaction. In: J. Pierre (Ed.) Debating Governance: Authority, Steering and Democracy. (Oxford: Oxford University Press), pp. $138-166$.

[3] Haas, P., 2002, UN conferences and constructivist governance of the environment. Global Governance, 8(1), 73-91.

[4] Van Kersbergen, K. and van Waarden, F., 2004, Governance as a bridge between disciplines: Cross-disciplinary inspiration regarding shifts in governance and problems of governability, accountability and legitimacy. European Journal of Political Research, 43, 143-171.

[5] Cadman, T., 2011, Quality and Legitimacy of Global Governance: Case Lessons from Forestry. (London and Basingstoke: Palgrave Macmillan, International Political Economy Series).

[6] Gulbrandsen, L., 2005, Mark of Sustainability? Challenges for fishery and forestry eco-labeling. Environment, 47(5), 8-23.

[7] Corbera, E. and Schroeder, H., 2011, Governing and implementing REDD+. Environmental Science and Policy, 14(2), 89-99.

[8] Barnett, J., 2010, Adapting to climate change: Three key challenges for research and policy - An editorial essay. Wiley Interdisciplinary Reviews. Climate Change, 1(3), 314-317.

[9] Lederer, M., 2012, From CDM to REDD+ - What do we know for setting up effective and legitimate carbon governance? Ecological Economics, doi:10.1016/j.ecolecon.2011.02.003. 
[10] Lyster, R., 2011, REDD+, transparency, participation and resource rights: The role of law. Environmental Science and Policy, 14, 118-126.

[11] Bebchuk, L. and Hamdani, A., 2009, The elusive quest for global governance standards. University of Pennsylvania Law Review, 157, 1263-1317.

[12] Whitman, J., 2005, The Limits of global governance. (Abington: Routledge).

[13] Ashbaugh-Skaife, H., Collins, D. and LaFond, R., 2006, The effects of corporate governance on firms' credit ratings. Journal of Accounting and Economics, 42, 203-243.

[14] Maraseni, T.N., 2013, Selecting a CDM investor in China: A critical analysis. Energy Policy, 53, 484-489.

[15] Maraseni, T.N. and Xu, G., 2010, An analysis of Chinese perceptions on unilateral Clean Development Mechanism projects. Environmental Science and Policy, 14(3), 339-346.

[16] UNFCCC (United Nations Framework Convention for Climate Change), 2012, Clean Development Mechanism, the United Nations Framework Convention on Climate Change. UNEP/WMO. Available online at: http://cdm.unfccc.int/index.html (accessed 30 November 2012).

[17] World Bank, 2008, State and trends of the carbon market 2008. Washington, DC, 78p. Available online at: http://siteresources.worldbank.org/ (accessed 16 May 2008).

[18] World Bank, 2009, State and trends of the carbon market 2009, Washington, DC, 78p. Available online at: $\mathrm{http} / / /$ siteresources.worldbank.org (accessed 6 November 2009).

[19] Kedia, B., Lahiri, S. and Mukherjee, D., 2006, BRIC economies: Earlier growth constraints, contemporary transformations and future potential, and key challenges. In: S. Jain (Ed.) Emerging Economies and the Transformation of International Business: Brazil, Russia, India, China (BRICS). (Cheltenham: Edward Elgar), pp. 46-74.

[20] World Bank, 2012, State and trends of the carbon market 2012. Washington, DC, 137p. Available online at: http://siteresources.worldbank.org (accessed 6 July 2012).

[21] High-Level Panel on the CDM Policy Dialogue, 2012a, Research report: Assessing the impact of the Clean Development Mechanism. Available online at: http://www.cdmpolicydialogue.org/report/rpt110912.pdf (accessed 17 October).

[22] High-Level Panel on the CDM Policy Dialogue, 2012b, Climate change, carbon markets and the CDM: A call to action report of the high-level panel on the CDM policy dialogue. ISBN 92-9219-100-4.

[23] Maraseni, T.N., 2013, Evaluating the clean development mechanism program, Chapter 6. In: T. Cadman (Ed.) Climate Change and Global Policy Regimes: Towards Institutional Legitimacy. (Palgrave Macmillan), pp. $96-110$.

[24] Teräväinen, T., 2009, The challenge of sustainability in the politics of climate change: A Finnish perspective on the Clean Development Mechanism. Politics, 29(3), 173-182.

[25] Sterk, W. and Wittneben, B., 2006, Enhancing the clean development through sectoral approaches definitions, applications and ways forward. International Environmental Agreements, 6, 271-287.

[26] CDM Policy Dialogue, 2012, Climate change, carbon markets and the CDM: A call to action. Report of the High-Level Panel on the CDM Policy Dialogue (Luxembourg: CDM Policy Dialogue).

[27] UN-REDD Programmme, 2010, The UN-REDD Programme. Available online at: http://www.un-redd.org/ UNREDDProgramme/tabid/583/language/en-US/Default.aspx (accessed on 23 March 2010).

[28] Angelsen, A., Brockhaus, M., Kanninen, M., Sills, E., Sunderlin, W. and Wertz-Kanounnikoff, S., 2009, Realising REDD, National Strategy and Policy Options. (Bogor: CIFOR).

[29] Parker, C., Mitchell, A., Trivedi, M. and Mardas, N., 2009, The Little REDD+ Book. (Oxford: Global Canopy Programme).

[30] Bleaney, A., Peskett, L. and Mwayafu, D., 2010, REDD-plus after Copenhagen: What does it mean on the ground? REDD-net COP 15 briefing, January 2010. Available online at: http://6823165678770790248-aredd-net-org-s-sites.googlegroups.com/a/redd-net.org/site/files/COP15outcome-webfinal.pdf (accessed 20 May 2010).

[31] Lesniewska, F., 2010, REDD: The Copenhagen effect. Law, Environment and Development Journal, 6(1), $104-111$.

[32] CIFOR (Centre for International Forestry Research), 2011, Starting the REDD+ dance. http://www.cifor.org/ forest-research/cancun-analysis-starting-the-redd-dance.html (accessed 17 January 2012).

[33] FCPC (Forest Carbon Partnership Facility), 2011, Forest Carbon Partnership Facility (FCPF) Readiness fund common approach to environmental and social safeguards for multiple delivery partners (FCPF).

[34] UN-REDD, 2012, UN-REDD Programme social and environmental principles and criteria. No location.

[35] Lammerts van Beuren, E.M. and Blom, E.M., 1997, Hierarchical framework for the formulation of sustainable forest management standards. (Leiden: The Tropenbos Foundation).

60 [36] Van Selm, M. and Jankowski, W., 2006, Conducting online surveys. Quality \& Quantity, 40(3), 435-456.

[37] Cadman, T. and Maraseni, T.N., 2012a, Perspectives on the quality of global environmental governance: An evaluation of NGO participation in global climate negotiations in the Asia Pacific and beyond. Third Sector Review, 18(1), 145-169.

[38] Cadman, T. and Maraseni, T.N., 2012b, The governance of REDD+: An institutional analysis in the Asia Pacific region and beyond. Journal of Environmental Planning and Management, 55(5), 617-635. 
[39] Cadman, T. and Maraseni, T.N., 2011, The governance of climate change: Evaluating the governance quality and legitimacy of the United Nations REDD-plus Programme. The International Journal of Climate Change: Impacts and Responses, 2(3), 103-123.

[40] Nanz, P. and Steffek, J., 2005, Deliberation and democracy in global governance: The role of civil society. In: Sophie Thoyer and Bénoit Martimort-Asso (Eds.) Participation for Sustainability in Trade. (London: Ashgate).

[41] IPCC (Intergovernmental Panel on Climate Change), 2014, "Technical summary of climate change: Mitigation of climate change", Working Group III Contribution to the IPCC Fifth Assessment Report (AR5).

[42] Ranspon, M. and Stavins, R.N., 2013, Linkage of Greenhouse Gas Emissions Trading Systems: Learning from Experience, Harvard Project on Climate Agreements. Discussion Paper ES 13-2, 44p.

[43] Maraseni, T.N., Maroulis, J. and Cockfield, G., 2009, An analysis of Australia's carbon pollution reduction scheme. International Journal of Environmental Studies, 66(5), 591-603.

[44] United Nations, 2014a, Doha amendment". Available online at: http://unfccc.int/kyoto_protocol/doha_amend ment/items/7362.php (accessed 04 July 2014).

[45] United Nations, 2014b, Kyoto Protocol. Available online at: https://unfccc.int/kyoto_protocol/items/2830.php (accessed 04 July 2014).

[46] Cadman, T., 2014, Introduction: Climate change and global policy regimes. In: T. Cadman (Ed.) Global Climate Change Policy: Towards Institutional Legitimacy. (London: Palgrave Macmillan), pp. 1-16.

[47] Cadman, T. and Maraseni, T., 2013, More equal than others? A comparative analysis of state and non-state perceptions of interest representation and decision-making in REDD+ negotiations. Innovation: The European Journal of Social Science Research, 26(3), 214-230.

[48] Maraseni, T.N., Neupane, P., Lopez-Casero, F. and Cadman, T., 2014, An assessment of the impacts of the REDD+ pilot project on community forests user groups (CFUGs) and their community forests in Nepal. Journal of Environmental Management, 136(2014), 37-46.

[49] Pandey, S., Maraseni, T.N. and Cockfield, G., 2014a, Carbon stock dynamics in different vegetation dominated community forests under REDD+: A case from Nepal. Forest Ecology and Management, 327, 40-47.

[50] Pandey, S., Maraseni, T.N. and Cockfield, G., 2014b, Dynamics of carbon and biodiversity under REDD+ regime: A case from Nepal. Environmental Science \& Policy, 38, 272-281.

[51] WRI (World Resources Institute), 2010, Reflections on the Cancún agreements. Available online at: http:// pdf.wri.org/reflections_on_cancun_agreements.pdf (accessed 17 January 2012). 